\title{
Single Bout of Yoga Practices (Asana) Effect on Low Frequency (LF) of Heart Rate Variability - A Pilot Study
}

\author{
Anup De ${ }^{1}$, Samiran Mondal ${ }^{1,2}$, Singh Deepeshwar ${ }^{2,3, *}$
}

\section{Anup De', Samiran \\ Mondal ${ }^{2}$, Singh \\ Deepeshwar ${ }^{3,4, *}$}

'Department of Physical Education and Sport Science, Visva-Bharati University, Santiniketan, West Bengal, INDIA. ${ }^{2}$ Department of Yogic Art and Science, Visva-Bharati, Santiniketan, West Bengal, INDIA.

${ }^{3}$ Department of Yoga and Life Science, Swami Vivekananda Yoga University (S-VYASA), Bangalore, Karnataka, INDIA.

\section{Correspondence}

Dr. Deepeshwar Singh,

Visiting Professor, Department of Yogic Arts and Sciences, Visva-Bharti, Santiniketan-731235, West Bengal, INDIA. Mobile no: +91080 22639906

Email: deepeshwar.singh@gmail.com

History

- Submission Date: 13-08-2019;

- Revised Date: 11-11-2019;

- Accepted Date: 19-11-2019;

DOI : 10.5530/ijmedph.2019.4.34

Article Available online

http://www.ijmedph.org/v9/i4

\section{Copyright}

(C) 2019 Phcog.Net. This is an openaccess article distributed under the terms of the Creative Commons Attribution 4.0 International license.

\begin{abstract}
The Heart Rate Variability (HRV) is an important parameter to assess psychophysiological changes associated with Autonomic Nervous System (ANS). The present study aimed to assess the effect of single bout yoga postures practice on parasympathetic nervous system activity of ANS. Three male subjects having more than 5 years of experience in yoga postures were selected in the current study. These participants were assessed for HRV immediately before and after practice of specific yoga postures practiced for $15 \mathrm{~min}, 21 \mathrm{~min}$ and $27 \mathrm{~min}$ on three different days. The yoga practices were selected from hatha yogic texts that may influence brain blood flow resulting autonomic activities.

Key words: Yoga Postures (asana), Autonomic nervous system, Heart rate variability, Low frequency, Single bout.

Key message: The regular practice of yogic postures improves autonomic modulation and enhances deep relaxation.
\end{abstract}

\section{INTRODUCTION}

Mind-body practices have been shown modulation in Heart Rate Variability (HRV) of practitioners. $\mathrm{HRV}$ is the promising and non-invasive measurement of instantaneous variation in heart rhythm due to physical and mental stress. The mind-body practices such as yoga, tai-chi, meditation, etc., facilitate autonomic balance in immediate or long-term practitioners. Higher HRV indicates greater parasympathetic control, whereas lower HRV indicates lesser parasympathetic control in the autonomic nervous system. ${ }^{1}$ Autonomic imbalance positively associated with aerobic exercise, physical activity, psychological and physiological flexibility and negatively associated with physical exhaustion, mental stress, psychological distress and physical strain. ${ }^{2}$

Previous studies on yoga reflected positive changes in various other markers of physiological health such as Heart Rate (HR), Galvanic Skin Resistance (GSR), baroreflex sensitivity and evoked potentials. ${ }^{1,3,4}$ Further, the association between yoga and HRV has been reported in clinical studies as well. But most of the studies on yoga and HRV is based on either meditation or breathing practices or integrated practice of yoga. Recently, there is a study on regular yoga practitioners affect HRV components and found during standing yoga postures there were increased in the LF power and decreased in the HF power and during inverted and forward bending postures showed opposite results i.e., decrease in the LF power and increase in the HF power. ${ }^{5,6}$ Other few earlier studies also reported that after yoga postures, there is a withdrawal of sympathetic arousal in regular yoga practitioners and reduced Heart Rate (HR). ${ }^{7,8}$ However, there is no investigation recorded the autonomic modulation in three different time periods (i.e., $15 \mathrm{~min}, 21 \mathrm{~min}$ and $27 \mathrm{~min}$ ) on different days in the same yoga practitioners in single bout of yoga posture practices. The selected postures are also supposed to enhance cognitive functions.

Therefore, the present study is designed to investigate the yoga postures intervention effect on the Parasympathetic Nervous System (PNS) using HRV indices.

\section{MATERIALS AND METHODS}

Three normal healthy male yoga practitioners (mean age of 25 years) willing to participate in this study after advertising in University notice board. These recruited participants were from the Post Graduate (PG) level and their socioeconomic status was lower middle class. The average height, weight and BMI were $163.16 \mathrm{~cm}, 61 \mathrm{~kg}$ and $22.9 \mathrm{~kg} / \mathrm{m}^{2}$ respectively. All participants had five years' experience in yoga practice. The HRV data were acquired using the NeXus-10 device (Medical Device Directive 93/42/EEC; TMS International BV, the Netherlands). The study was approved by ethical committee of the University and signed informed consent form was obtained from each participants.

\section{Study design}

The design of the study was pre-post repetitive assessments where all three participants underwent for three intervention conditions, i.e., $15 \mathrm{~min}, 21 \mathrm{~min}$
Cite this article : De A, Mondal S, Deepeshwar S. Single Bout of Yoga Practices (Asana) Effect on Low Frequency (LF) of Heart Rate Variability - A Pilot Study. Int J Med Public Health. 2019;9(4):160-3. 
and $27 \mathrm{~min}$ practice of yoga. The data were collected immediately before and after yoga postures practice on three consecutive days but at the same time of the day. The schematic representation of the design is shown in Figure 1.

\section{Assessments}

Heart Rate Variability (HRV): The HRV outcomes included LF in percentage (\%), HF\% and amplitude recorded in Hz unit. The HRV spectrum contains two major components: The High Frequency (HF) (0.18$0.4 \mathrm{~Hz}$ ) component, which is synchronous with respiration. The second is a Low Frequency (LF) (0.04 to $0.15 \mathrm{~Hz}$ ) component that appears to be mediated by both the vagus and cardiac sympathetic nerves. Highfrequency (HF) activity has been found to decrease under conditions of acute time pressure and emotional strain and elevated state anxiety, presumably related to focused attention and motor inhibition. ${ }^{8,9}$

\section{Intervention}

The five yoga postures (asanas) were selected for the present study which is associated with brain functions. ${ }^{10}$ Each yoga posture (asana) was performed for an allotted time and repetition cycles accordingly. The details of the yoga practices protocol are shown in Table 1.

\section{Statistical Analysis}

The obtained data were analyzed with descriptive statistics viz. mean, standard deviation and standard error of the mean and percentage changes. However, paired ' $t$ ' test was not applied to determine the statistical significance of differences due to the very small sample size.

\section{RESULTS}

The outcome of the HRV components showed there was an increase in LF \% band and decrease in HF \% band immediately after 15 min and 21 min practice of yoga postures. But there was a decrease in LF\% band after 27 min yoga postures practice. Another component of HRV was HRV amplitude, which showed a trend towards a decrease in $21 \mathrm{~min}$ and 27 min of yoga postures. The mean, Standard Deviations (SD) and Standard Error Mean (SEM) of HRV components are given in Table 2. The heart rate variability before and after yogasana practice is depicted in Figure 2 (LF\%), Figure 3 (HF\%) and Figure 4 HRV amplitude.

\section{DISCUSSION}

The results of the present study showed that the $15 \mathrm{~min}$ and $21 \mathrm{~min}$ of yoga postures (asana) practice increases in the low frequency (LF\%) band and decreases high frequency (HF\%). Whereas, after $27 \mathrm{~min}$ of yoga postures there were decreased in the LF\% band and HRV amplitude. Typically, LF band (0.04-0.15 Hz) mainly reflects baroreceptor activity and sympathetic activity during rest and exercise ${ }^{8,11}$ and other studies have reported no change in LF and LF-HF ratio during exercise. ${ }^{12}$ The increased HF band suggests an increase in the vagal activity (parasympathetic) whereas the increased sympathetic activity is associated with LF band of HRV. ${ }^{8}$ Generally, the sympathetic activation is required during vigilance and considered necessary to perform an attentional task, while efferent vagal (parasympathetic) activity especially seen in clinical and experimental observations of autonomic maneuvers such as electrical vagal stimulation, muscarinic receptor blockade and vagotomy. ${ }^{13}$ But the embedded mechanism of yoga practice effect on the autonomic nervous system is not fully explored. Few studies speculated that after yoga postures there is stimulation of the vagus nerve and en-

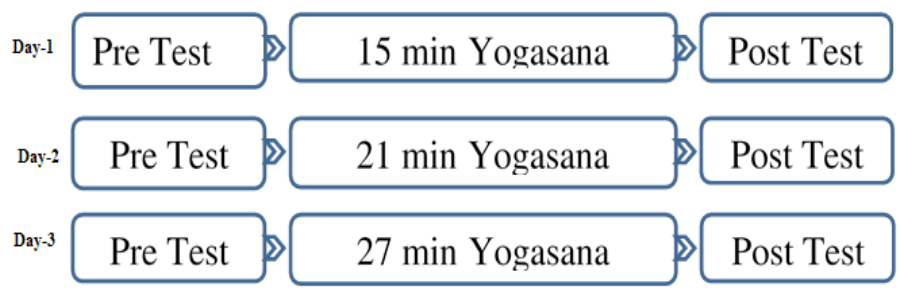

Figure 1: Pre-Test - Post Test Experimental Design.






\begin{tabular}{|c|c|c|c|c|c|c|c|}
\hline \multirow{2}{*}{ Duration } & & \multicolumn{2}{|c|}{ LF $\%$} & \multicolumn{2}{|c|}{ HF \% } & \multicolumn{2}{|c|}{ HRV Amplitude } \\
\hline & & Mean (SD) & SEM & Mean (SD) & SEM & Mean (SD) & SEM \\
\hline \multirow{2}{*}{15 Min } & Pre-Test & $45.33(17.51)$ & 10.11 & $54.67(17.51)$ & 10.11 & $9.15(1.56)$ & 0.90 \\
\hline & Post Test & $46.14(17.26)$ & 9.96 & $53.86(17.26)$ & 9.96 & $9.29(2.19)$ & 1.26 \\
\hline \multirow{2}{*}{$21 \mathrm{Min}$} & Pre-Test & $39.97(24.15)$ & 13.94 & $60.03(24.15)$ & 13.94 & $8.88(2.56)$ & 1.48 \\
\hline & Post Test & 45.49 (29.69) & 17.14 & $54.51(29.69)$ & 17.14 & $8.50(2.77)$ & 1.60 \\
\hline \multirow{2}{*}{27 Min } & Pre-Test & $49.44(21.14)$ & 12.20 & $50.56(21.14)$ & 12.20 & $9.84(2.60)$ & 1.50 \\
\hline & Post Test & $43.45(16.28)$ & 9.40 & $56.55(16.28)$ & 9.40 & $8.10(1.77)$ & 1.02 \\
\hline
\end{tabular}

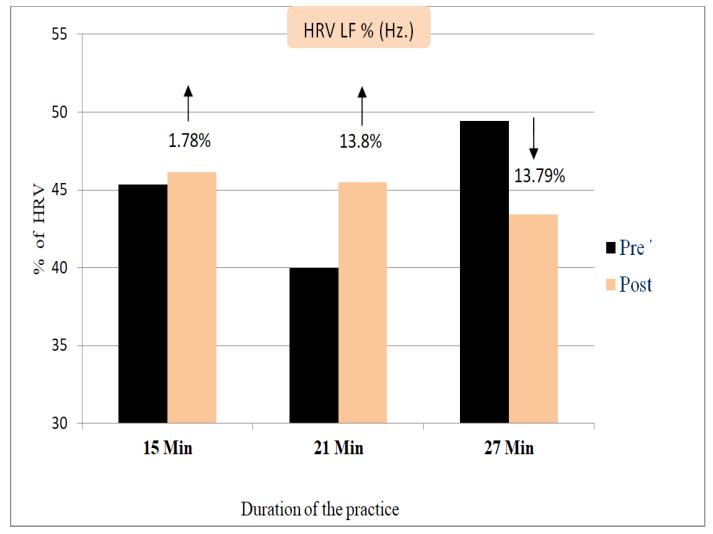

Figure 2: Heart rate variability (LF \%) after $15 \mathrm{~min}, 21 \mathrm{~min}$ and $27 \mathrm{~min}$ of yogasana practice.

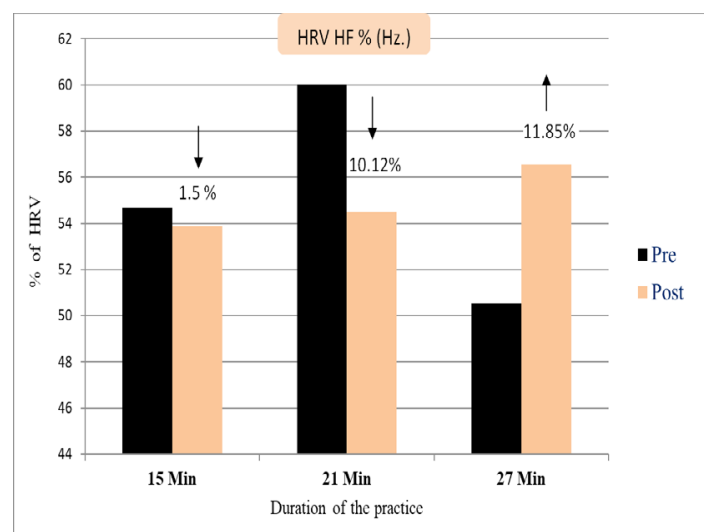

Figure 3: Heart rate variability (HF \%) after $15 \mathrm{~min}, 21 \mathrm{~min}$ and $27 \mathrm{~min}$ of yogasana practice.

hance parasympathetic outflow and control sensory input to the brain and enhanced mood and reflecting in cardiac functions. ${ }^{14}$ Few studies have been reported that a well-balanced vagal activity in long-term yoga practitioners where yoga practices consisted of physical postures (asana), breathing practices (pranayama), meditation (dhyana) and relaxation. ${ }^{715}$ In contrast to previous studies, the current study showed the sympathetic arousal and baroreflex activity after 15 and 21 min practice and decreased after 27 min practice of only yoga postures, which suggest that the long-term practice may modulate the autonomic activity and increase vagal tone. As mentioned by the Sage Patanjali in Yoga Sutra (PYS), that when an individual practice yoga postures (asana) for a

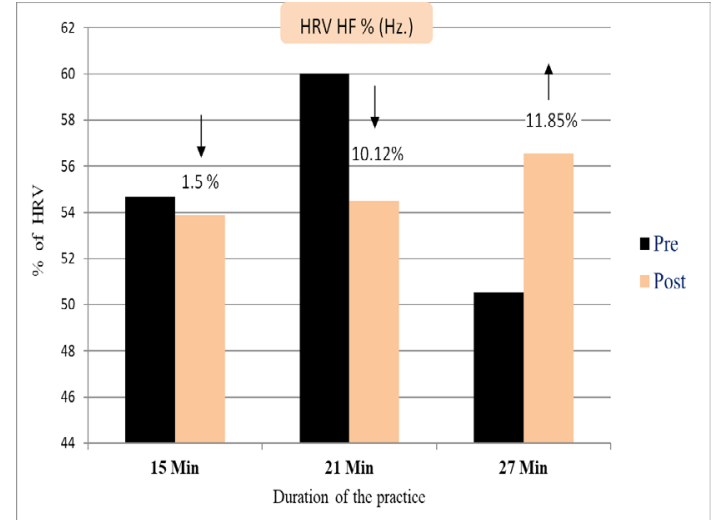

Figure 4: Heart rate variability amplitude after $15 \mathrm{~min}, 21 \mathrm{~min}$ and $27 \mathrm{~min}$ of yogasana practice.

longer duration, the practice becomes steady, stable and firm that leads to ease and comfortable which enhances pleasure and relaxation (PSY Chapter 2- Verses 46-47). ${ }^{16}$ The outcome of the present study followed the ancient literature also reflects that the regular and repeated practice of yoga may enhance relaxation and increases parasympathetic outflow. This outcome may be helpful for cognitive behavior and emotional responses. The limitations of the study are straightforward including, the small sample size; absence of the control group and self as control design. Therefore, further study can be done using an adequate sample size, with complete autonomic and neurophysiological assessments such as Electroencephalogram (EEG), Functional Near-Infrared Spectroscopy (fNIRS) and Evoked Potentials (EPs).

\section{ACKNOWLEDGEMENT}

The researchers are thankful to University Grant Commission, Ministry of Human Resource Development, Govt. of India for their financial support in this project. We are also thankful to Department of Yogic Art and Science, Visva-Bharati, Central University, for providing participants.

\section{CONFLICT OF INTEREST}

The authors declare no Conflict of interest

\section{ABBREVIATIONS}

HRV: Heart Rate Variability; LF: Low Frequency; HF: High Frequency; 
ANS: Autonomic Nervous System; PNS: Parasympathetic Nervous System; GSR: Galvanic Skin Resistance; HR: Heart Rate; SD: Standard Deviation.

\section{REFERENCES}

1. Cheema BS, Marshall PW, Chang D, Colagiuri B, Machliss B. Effect of an office worksite-based yoga program on heart rate variability: A randomized controlled trial. BMC Public Health. 2011;11(1):578. doi:10.1186/1471-2458-11-578

2. Friis AM, Sollers JJ. Yoga Improves Autonomic Control in Males: A Preliminary Study Into the Heart of an Ancient Practice. J Evidence-Based Complement Altern Med. 2013;18(3):176-82. doi:10.1177/2156587212470454

3. Bowman AJ, Clayton RH, Murray A, Reed JW, Subhan MM, Ford GA. Effects of aerobic exercise training and yoga on the baroreflex in healthy elderly persons. Eur J Clin Invest. 1997;27(5):443-9.

4. Bhavanani A, Pal G, Udupa K, Krishnamurthy N, Trakroo M. A comparative study of the effects of asan, pranayama and asan-pranayama training on neurological and neuromuscular functions of Pondicherry police trainees. Int J Yoga. 2013;6(2):96. doi:10.4103/0973-6131.113398

5. Manjunath NK, Telles S. Effects of Sirsasana (headstand) practice on autonomic and respiratory variables. Indian J Physiol Pharmacol. 2003:47(1):34-42.

6. Kulkarni R, Nagarathna R, Nagendra $H, A n$. Measures of heart rate variability in women following a meditation technique. Int J Yoga. 2010;3(1):6. doi:10.4103/0973-6131.66772

7. Khattab K, Khattab AA, Ortak J, Richardt G, Bonnemeier H. Iyengar Yoga increases cardiac parasympathetic nervous modulation among healthy yoga practitioners. Evidence-based Complement Altern Med. 2007;4(4):511-7. doi:10.1093/ecam/nem087

8. Billman GE. The LF/HF ratio does not accurately measure cardiac sympathovagal balance. Front Physiol. 2013;4(2):26. doi:10.3389/fphys.2013.00026

9. Jönsson P. Respiratory sinus arrhythmia as a function of state anxiety in healthy individuals. Int J Psychophysiol. 2007;63(1):48-54. doi:10.1016/j.ijpsycho.2006.08.002

10. Saraswati S. Asana Pranayama Mudra Bandha. Yoga Publications Trust. 2013.

11. Electrophysiology TF o.t. ES o.t. NAS. Heart Rate Variability: Standards of Measurement, Physiological Interpretation and Clinical Use. Circulation. 1996;93(5):1043-65. doi:10.1161/01.CIR.93.5.1043

12. Yamamoto $Y$, Hughson RL, Peterson JC. Autonomic control of heart rate during exercise studied by heart rate variability spectral analysis. J Appl Physiol. 1991;71(3):1136-42. doi:10.1152/jappl.1991.71.3.1136

13. Subramanya P, Telles S. Performance in the Stroop Task and Simultaneously Recorded Heart Rate Variability before and after Meditation, Supine Rest and No-Intervention. Int J Brain Cogn Sci. 2015;4(1):8-14. doi:10.5923/j. ijbcs.20150401.03

14. Innes KE, Bourguignon C, Taylor AG. Risk indices associated with the insulin resistance syndrome, cardiovascular disease and possible protection with yoga: A systematic review. J Am Board Fam Pr. 2005;18(6):491-519. doi:18/6/491 [pii]

15. Muralikrishnan K, Balakrishnan B, Balasubramanian K, Visnegarawla F. Measurement of the effect of Isha Yoga on cardiac autonomic nervous system using short-term heart rate variability. J Ayurveda Integr Med. 2012;3(2):91. doi:10.4103/0975-9476.96528

16. Taimni IK. The Science of Yoga: The Yoga-Sūtras of Patañjali in Sanskrit with Transliteration in Roman, Translation and Commentary in English. Madras: Theosophical Publishing House. 1999.

Cite this article : De A, Mondal S, Deepeshwar S. Single Bout of Yoga Practices (Asana) Effect on Low Frequency (LF) of Heart Rate Variability - A Pilot Study. Int J Med Public Health. 2019;9(4):160-3. 